\title{
REMOÇÃO DE CÁTIONS METÁLICOS UTILIZANDO ZEÓLITA HUSY
}

Fabricio Ventura Barsi - fabricio_barsi@yahoo.com.br Universidade Estadual do Centro-Oeste do Paraná - UNICENTRO 


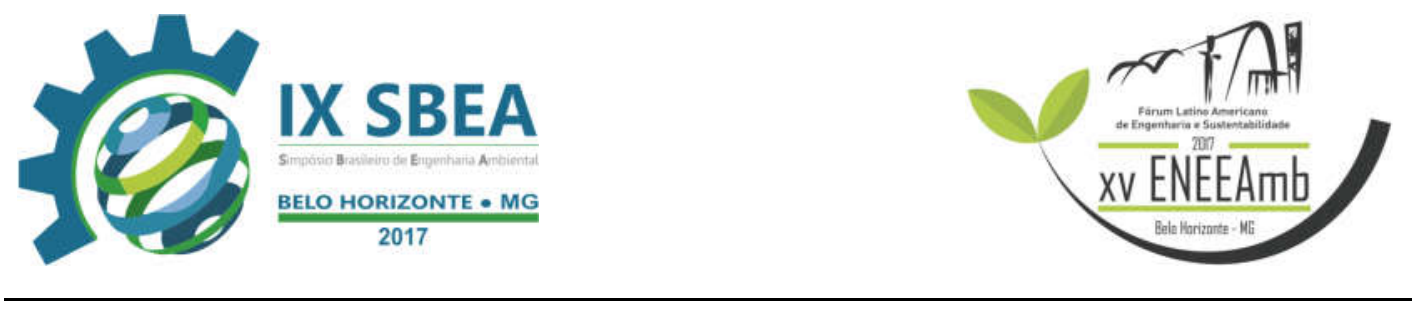

\section{RESUMO}

Neste trabalho foi estudada a remoção dos cátions de cobalto, cobre, zinco, níquel, cromo, chumbo e cádmio pela zeólita comercial HUSY CBV720. Todos os experimentos foram realizados em batelada, tanto para os estudos de determinação de tempo de equilíbrio de adsorção e de $\mathrm{pH}$ realizados à temperatura de $25^{\circ} \mathrm{C}$ como para as obtenções das isotermas de adsorção para os cátions metálicos à $25^{\circ} \mathrm{C}, 35^{\circ} \mathrm{C} \mathrm{e} 45^{\circ} \mathrm{C} \mathrm{em} \mathrm{pH}=7$. Os resultados obtidos apontaram que o zinco, o cobre e o cobalto apresentaram uma capacidade de adsorção até 4 vezes maior que os outros cátions na zeólita e em maiores concentrações de metais no efluente modelo utilizando as mesmas condições de adsorção na zeólita HUSY.

Palavras-chave: Adsorção, Cátions Metálicos, Zeólita.

\section{INTRODUÇÃO/OBJETIVO}

A poluição causada por despejos industriais de origem orgânica ou inorgânica, tornou-se há tempos um motivo de preocupação, isso porque em muitos desses efluentes encontram-se substâncias, como os íons de metais ou nutrientes (nitrogênio e fósforo), que não são removidos por tratamentos biológicos já existentes e dessa forma colaboram cada vez mais para a deterioração da qualidade da água de rios, lagos e mares (PERGHER et al., 2005).

Os metais representam uma importante fonte de contaminação dos corpos d'água, muitas vezes impossibilitando o uso dessa água para consumo humano, devido a alta demanda bioquímica de oxigênio que exercem. Por serem não degradáveis, consequentemente sofrem o efeito denominado de amplificação biológica, e dependendo da concentração quando atingem o homem provocam efeitos adversos à saúde; isso inclui o câncer, a mutação, além de ataques ao sistema imunológico (AGUIAR e NOVAES, 2002; JIMENEZ et al., 2004).

Tendo o conhecimento de que os métodos clássicos de tratamento de efluentes são ineficientes na remoção de íons metálicos, e levando em consideração a atual legislação ambiental (cada vez mais rigorosa) métodos alternativos vêm sendo investigados. Destacam-se as membranas filtrantes e a adsorção em zeólitas, essa última vem 


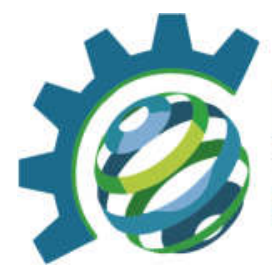

merecendo atenção devido ao seu baixo custo e simplicidade operacional (PERGHER et al., 2005).

Por definição, zeólitas são estruturas cristalinas tridimensionais de tetraedros de $\mathrm{SiO}_{4}$ e de $\mathrm{AlO}_{4}$, conectados pelos átomos de oxigênio nos vértices, sendo que cada átomo de oxigênio pertence a dois tetraedros. Como o alumínio apresenta valência $(3+)$ menor do que a do silício (4+), a estrutura do aluminossilicato apresenta uma carga negativa para cada átomo de alumínio. Nessa configuração, as cargas negativas dos tetraedros de $\mathrm{AlO}_{4}$ são compensadas por cátions de metais alcalinos ou alcalinos terrosos $\left(\mathrm{Na}^{+}, \mathrm{K}^{+}, \mathrm{Ca}^{2+} \mathrm{e}\right.$ $\mathrm{Ba}^{2+}$ ), que são passíveis de troca. (AGUIAR e NOVAES, 2002; JIMENEZ et al., 2004; SHINZATO, 2007; JORDÃO, 2001).

A zeólita Y é pertencente à família das faujasitas e possui um sistema de arranjo cristalino tridimensional cúbico. Esta zeólita apresenta um parâmetro de cela unitária que varia entre 24,18 e 25,00 ̊̊ quando a mesma se encontra na forma sódica e hidratada, dependendo da razão Si/Al (BRECK, 1974). A união dos prismas hexagonais com quatro das faces hexagonais da sodalita forma um poliedro dentro do qual se encontra a supercavidade $\alpha$. A estrutura cristalina da família das faujasitas é mostrada na Figura 1.

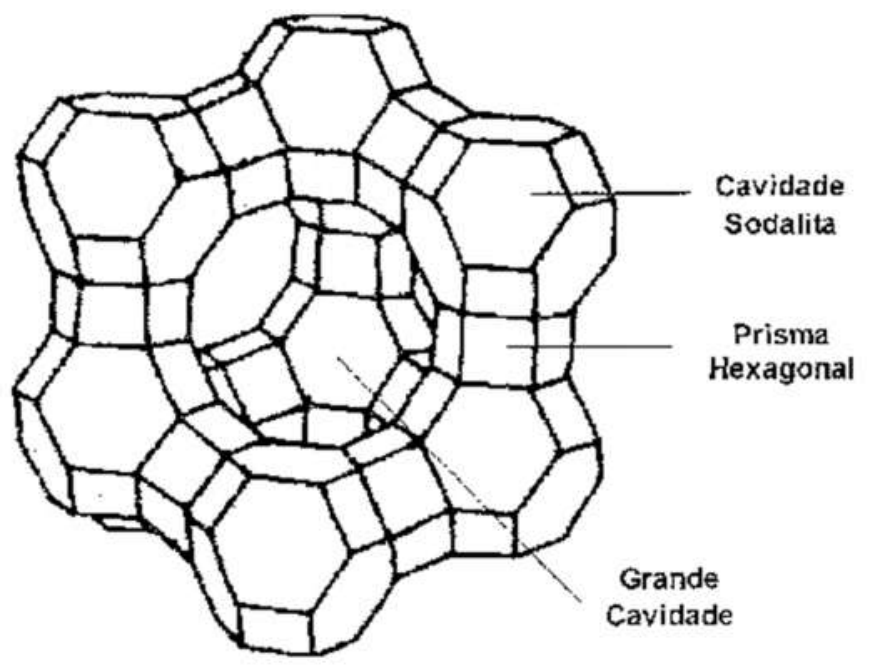

Figura 1. Estrutura cristalina da zeólita Y (SOBRINHO, 1993). 


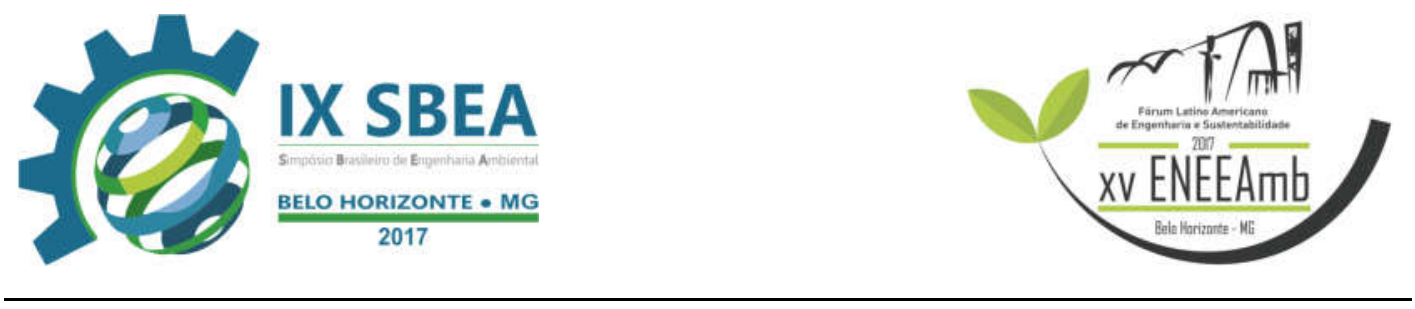

Em sua estrutura as zeólitas possuem canais e cavidades interconectadas de dimensões moleculares, na onde se encontram os íons de compensação, outros adsorvatos ou moléculas de água e sais, e é essa estrutura microporosa que atribui a zeólita uma superfície interna elevada na comparação com a superfície externa. Essa estrutura cristalina com cavidades espaçosas permite uma alta eficiência das zeólitas no processo de adsorção (LUZ, 1995).

O objetivo deste trabalho foi avaliar a remoção de cátions metálicos $\left(\mathrm{Zn}^{2+}, \mathrm{Co}^{2+}\right.$, $\mathrm{Cu}^{2+}, \mathrm{Pb}^{2+}, \mathrm{Cd}^{2+}, \mathrm{Cr}^{3+}, \mathrm{Ni}^{2+}$ ) através de adsorção em zeólita HUSY.

\section{METODOLOGIA}

Preparação do Efluente.

Foram utilizadas soluções de zinco, cobalto, cádmio, cobre, chumbo, cromo e níquel, preparadas a partir dos sais nas suas formas hidratadas em concentrações variadas.

Como material adsorvente foi empregada a zeólita comercial USY CBV720 adquirida junto à empresa Zeolyst International na sua forma protônica (HUSY), com razão molar $\mathrm{SiO}_{2} / \mathrm{AlO}_{3}$ igual a 30 e de área superficial igual a $780 \mathrm{~m}^{2} / \mathrm{g}$.

\section{Determinação do Tempo do Equilíbrio de Adsorção.}

Para a realização dos experimentos de determinação do tempo do equilíbrio de adsorção foram utilizados $500 \mathrm{~mL}$ da solução contendo os cátions metálicos $\left(\mathrm{Zn}^{2+}, \mathrm{Co}^{2+}\right.$, $\left.\mathrm{Cu}^{2+}, \mathrm{Pb}^{2+}, \mathrm{Cd}^{2+}, \mathrm{Cr}^{3+}, \mathrm{Ni}^{2+}\right)$ com concentrações em $100 \mathrm{mg} / \mathrm{L}$ adicionando $1 \mathrm{~g}$ da zeólita e pH igual a 7, as soluções permaneceram com agitação magnética constante e foram coletadas alíquotas de $20 \mathrm{~mL}$ em intervalos de tempos pré-estabelecidos: 0,5, 1, 2, 4, 6 e 24 horas.

\section{Estudo da Influência do $\mathrm{pH}$.}

Para a realização do estudo de $\mathrm{pH}$ ótimo de adsorção foram utilizados $500 \mathrm{~mL}$ da solução contendo os metais $\left(\mathrm{Zn}^{2+}, \mathrm{Co}^{2+}, \mathrm{Cu}^{2+}, \mathrm{Pb}^{2+}, \mathrm{Cd}^{2+}, \mathrm{Cr}^{3+}, \mathrm{Ni}^{2+}\right)$ adicionando $1 \mathrm{~g}$ da zeólita, as soluções com concentrações em $100 \mathrm{mg} / \mathrm{L}$ permaneceram com agitação magnética constante pelo tempo apontado pela determinação do tempo de equilíbrio para cada metal, a $25^{\circ} \mathrm{C}$, variando $\mathrm{pH}$ em $5,6,7,8$ e 9.

Isoterma de Adsorção. 


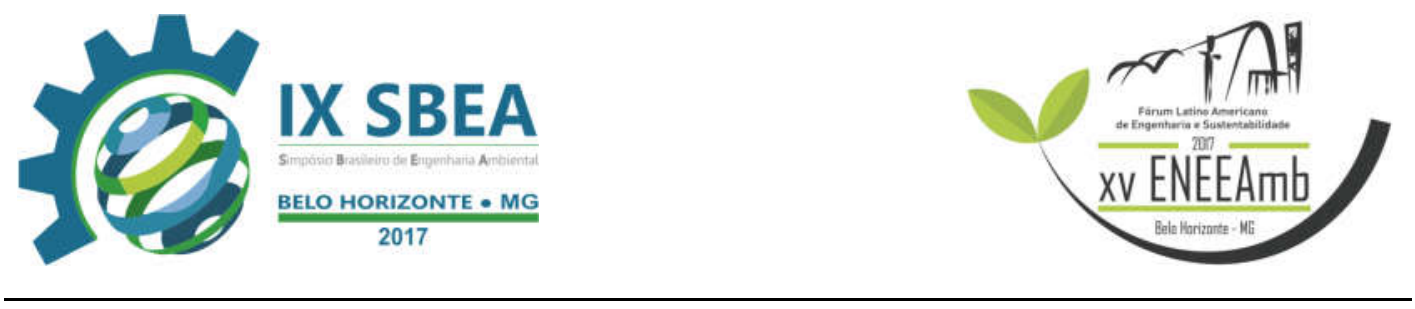

Os ensaios para determinação da isoterma de adsorção para cada metal $\left(\mathrm{Zn}^{2+}\right.$, $\left.\mathrm{Co}^{2+}, \mathrm{Cu}^{2+}, \mathrm{Pb}^{2+}, \mathrm{Cd}^{2+}, \mathrm{Cr}^{3+}, \mathrm{Ni}^{2+}\right)$ foram realizados com $1 \mathrm{~g}$ de zeólita e $500 \mathrm{~mL}$ de solução em batelada com agitação constante, $\mathrm{pH}=7$, por 1 ou 2 horas, dependendo do cátion metálico e de seu tempo para atingir o equilíbrio de adsorção, em três temperaturas diferentes, $25^{\circ} \mathrm{C}, 35^{\circ} \mathrm{C}$ e $45^{\circ} \mathrm{C}$, variando-se a concentração das soluções contendo metais em: $10,35,50,100,150,200,500$ e $1000 \mathrm{mg} / \mathrm{L}$ para cada temperatura.

Todas as alíquotas obtidas foram filtradas a vácuo para separar a zeólita do filtrado para posterior análise por espectrofotometria de absorção atômica com chama em um equipamento Varian, modelo Spectra A640.

\section{RESULTADOS E DISCUSSÃO}

A quantidade de íons metálicos adsorvidos $\left(\mathrm{Q}_{\mathrm{e}}\right)$ foi calculada através do decréscimo da concentração de íons metálicos no meio, considerando o volume de adsorção e a quantidade de zeólita empregada:

$$
Q_{e}=\frac{\left(C_{0}-C_{e}\right) \cdot V}{m}
$$

onde $\mathrm{C}_{0}$ e $\mathrm{C}_{\mathrm{e}}$ são respectivamente as concentrações da fase aquosa antes e depois do período de tratamento com a zeólita $(\mathrm{mg} / \mathrm{L})$; V é o volume da fase aquosa (L) e m é a quantidade de zeólita empregada em (g). (PERGHER et al., 2005).

O resultado da determinação do tempo de equilíbrio de adsorção dos cátions metálicos sobre a zeólita HUSY realizado à temperatura ambiente é apresentado na Figura 2. Como pode ser observado, o tempo mínimo necessário para obtenção do equilíbrio de adsorção foi de 1 hora para o $\mathrm{Co}^{2+}, \mathrm{Cu}^{2+}, \mathrm{Pb}^{2+}, \mathrm{Cr}^{3+}$ e o $\mathrm{Cd}^{2+}$ e de 2 horas para o $\mathrm{Zn}^{2+}$ e o $\mathrm{Ni}^{2+}$. Desta forma, como garantia foi utilizado o tempo de 2 horas para todos os ensaios de equilíbrio. 

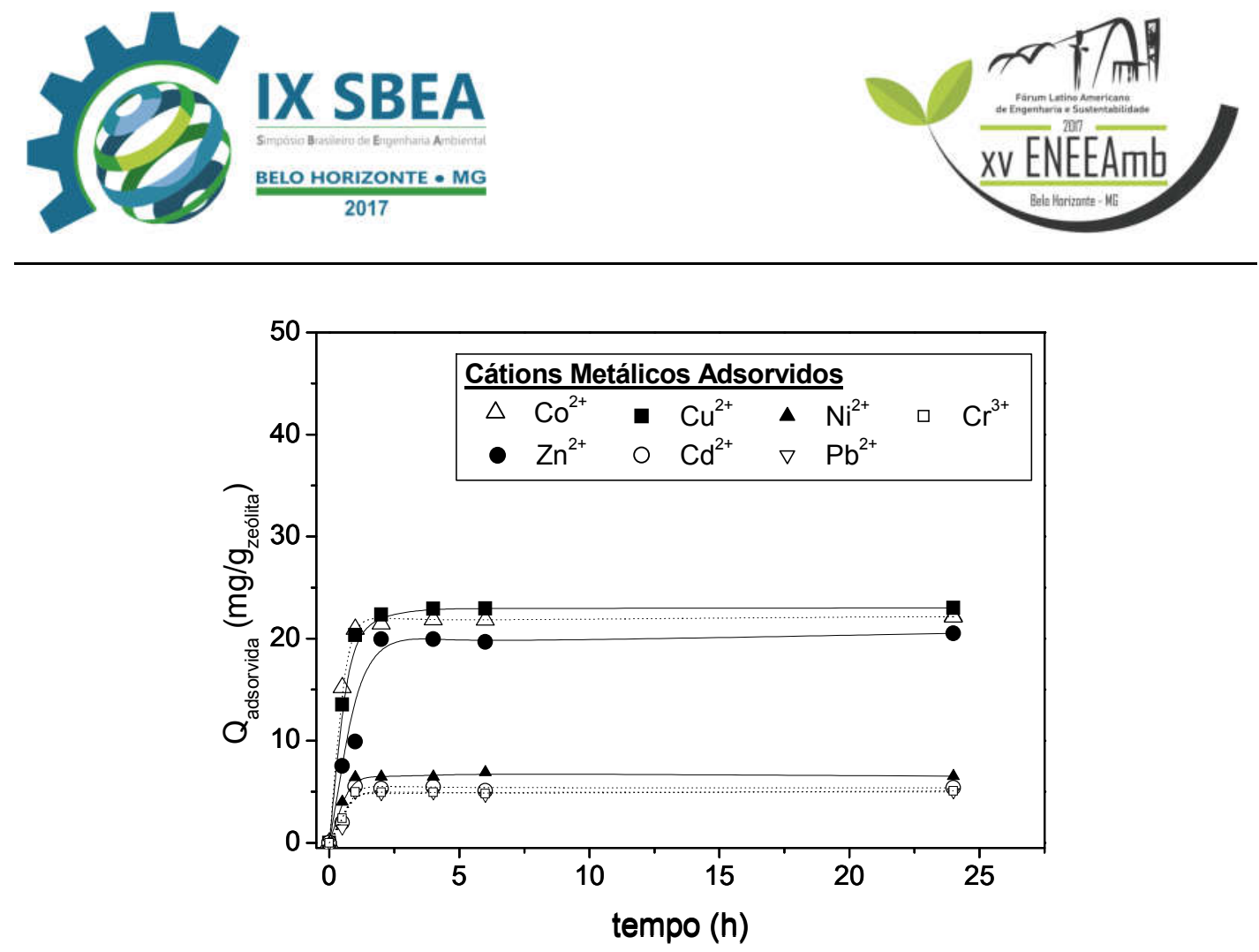

Figura 2. Determinação do tempo de equilíbrio de adsorção dos cátions $\mathrm{Co}^{2+}, \mathrm{Cu}^{2+}, \mathrm{Zn}^{2+}$, $\mathrm{Pb}^{2+}, \mathrm{Ni}^{2+}, \mathrm{Cr}^{3+}$ e $\mathrm{Cd}^{2+}$ sobre zeólita HUSY em temperatura ambiente.

Na Figuras 3 é apresentado os resultados do estudo de $\mathrm{pH}$ do processo de adsorção dos cátions metálicos com concentração de $100 \mathrm{mg} \cdot \mathrm{L}^{-1}$ e $25^{\circ} \mathrm{C}$ para a zeólita HUSY.

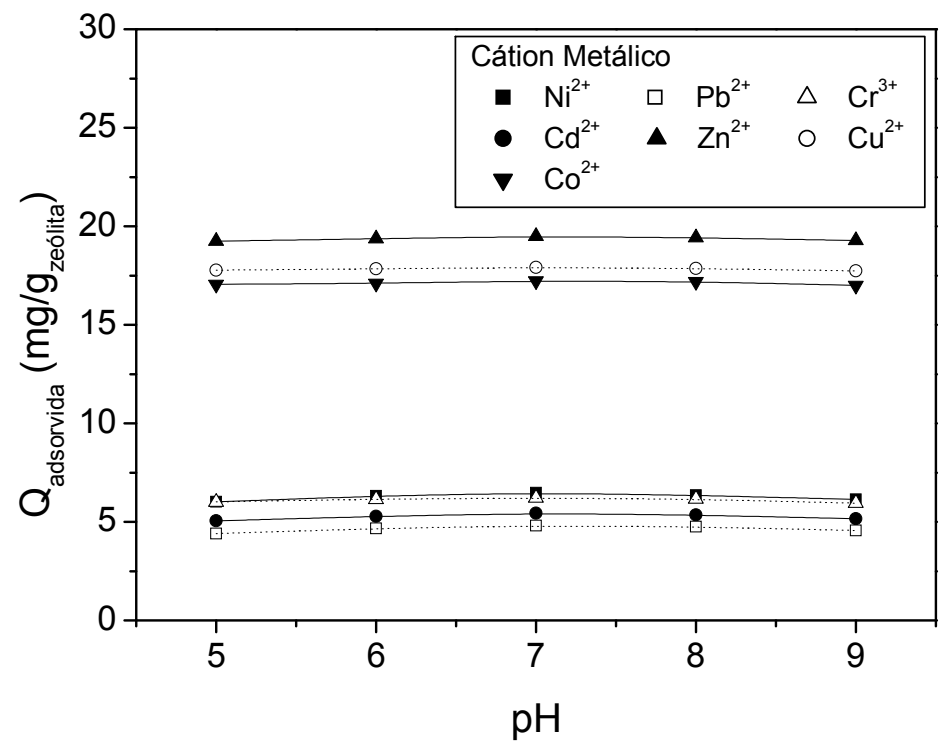

Figura 3. Estudo do $\mathrm{pH}$ na adsorção dos cátions $\mathrm{Co}^{2+}, \mathrm{Cu}^{2+}, \mathrm{Zn}^{2+}, \mathrm{Pb}^{2+}, \mathrm{Ni}^{2+}, \mathrm{Cr}^{3+} \mathrm{e} \mathrm{Cd}^{2+}$ sobre zeólita HUSY a $25^{\circ} \mathrm{C}$. 


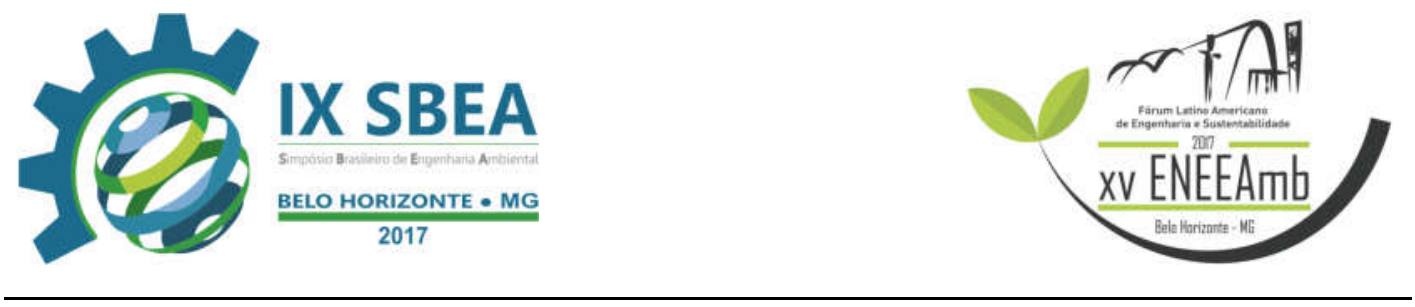

O resultado do estudo do $\mathrm{pH}$ das soluções com cátions metálicos apontou que o pH não apresentou significativa influência na adsorção dos cátions na zeólita HUSY, sendo utilizado para todos os ensaios posteriores o $\mathrm{pH} 7$, pois, pela legislação vigente (BRASIL, 2011), o valor do $\mathrm{pH}$ final do efluente deve ficar em torno desse valor.

As isotermas de adsorção dos cátions metálicos sobre a zeólita HUSY foram determinadas através das quantidades adsorvidas em função da concentração de equilíbrio das espécies em solução. Na Figuras 4 é apresentada as isotermas de adsorção de todos os cátions metálicos realizadas em $\mathrm{pH}$ igual à 7,0 à $25^{\circ} \mathrm{C}$.

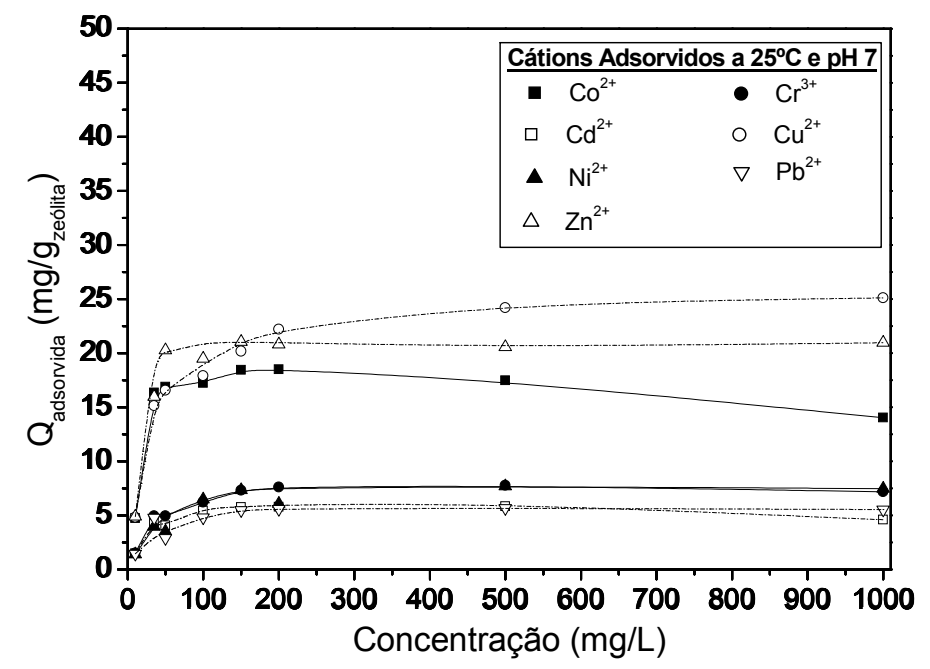

Figura 4. Isotermas de adsorção dos cátions $\mathrm{Co}^{2+}, \mathrm{Cu}^{2+}, \mathrm{Zn}^{2+}, \mathrm{Pb}^{2+}, \mathrm{Ni}^{2+}, \mathrm{Cr}^{3+} \mathrm{e} \mathrm{Cd}^{2+}$ sobre zeólita HUSY na temperatura de $25^{\circ} \mathrm{C}$ e $\mathrm{pH}=7$.

$\mathrm{Na}$ temperatura de $25^{\circ} \mathrm{C}$ o cátion metálico que adsorveu em maior quantidade de forma geral foi o zinco e o cobre (chegando a adsorver 4 vezes mais do que os demais cátions metálicos em maiores concentrações de metais no efluente modelo) utilizando as mesmas condições de adsorção na zeólita HUSY. O cobalto apresentou quantidades adsorvidas semelhantes, enquanto os outros cátions, $\mathrm{Cd}^{2+}, \mathrm{Ni}^{2+}, \mathrm{Cr}^{3+}$ e $\mathrm{Pb} 2+$, adsorveram somente em pequenas quantidades durante os ensaios. Ainda é possível, pelo gráfico, notar que para as sete soluções contendo metais utilizadas, a quantidade adsorvida sobre a zeólita alcança um patamar máximo da capacidade de adsorção por vezes diminuindo a 


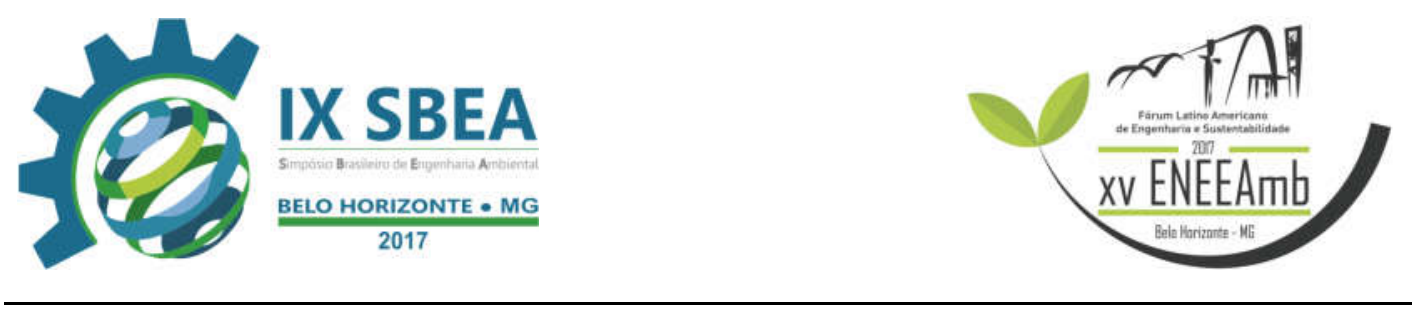

percentagem de adsorção na zeólita mesmo aumentando a concentração do efluente, ou seja, pode-se inferir que a zeólita HUSY não consegue mais adsorver esses cátions metálicos indicando uma possível saturação da superfície e dos microporos da zeólita. Esse comportamento também pode ser observado nas temperaturas de $35^{\circ} \mathrm{C}$ e $45^{\circ} \mathrm{C}$.

As quantidades máximas adsorvidas para todos os metais na zeólita HUSY ocorreram na concentração de metal entre $200 \mathrm{mg} / \mathrm{L}$ e $500 \mathrm{mg} / \mathrm{L}$, são essas quantidades máximas adsorvidas para a zeólita HUSY: $25 \mathrm{mgCu}^{2+} / \mathrm{g}_{\text {zeólita, }} 21 \mathrm{mgZn}{ }^{2+} / \mathrm{g}_{\text {zeólita, }} 18$ $\mathrm{mgCo}^{2+} / \mathrm{g}_{\text {zeólita }}$ e em torno de 4,5 a $7 \mathrm{mgMe}^{\mathrm{n}+} / \mathrm{g}_{\text {zeólita }}$ para o cádmio, níquel, chumbo e cromo.

Resultados similares aos obtidos neste trabalho para as quantidades adsorvidas de metais podem ser encontrados na literatura. Pergher e colaboradores (2005) em um estudo envolvendo remoção de $\mathrm{Cu}^{2+}$ em soluções aquosas com a zeólita $\mathrm{NaX}$ obtiveram uma

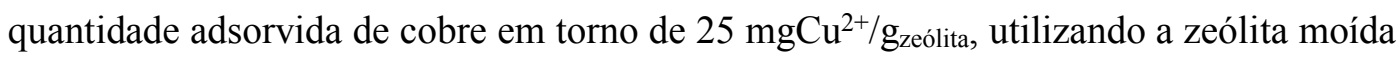
e $200 \mathrm{mg} / \mathrm{L}$ como concentração inicial de solução, na temperatura de $50^{\circ} \mathrm{C}$. Em outro trabalho mais antigo Fungaro e colaboradores (2002) obtiveram $25 \mathrm{mg}$ de $\mathrm{Cu} / \mathrm{g}$ como capacidade máxima de adsorção utilizando zeólitas preparadas com cinzas de carvão.

Para a remoção de zinco por adsorção utilizando como adsorvente a zeólita beta (BEA) em um compósito com óxido de ferro, obtendo em torno de 15 $\mathrm{mgZn}{ }^{2+} /$ gcompósito como capacidade máxima de adsorção (PERGHER, 2005).

Tagliaferro e colaboradores (2011) obteve valores semelhantes da capacidade de adsorção máxima para cátions $\mathrm{Cd}^{2+}$ utilizando óxido de nióbio hidratado como material adsorvente, esses autores chegaram ao valor de $8,85 \mathrm{mg} / \mathrm{g}_{\text {óxido, }}$ explicando que a menor afinidade do cátion com o adsorvente se deve pela baixa eletronegatividade e maior estabilidade do $\mathrm{Cd}^{2+}$ em solução.

Na Figura 5 é apresentada as isotermas de adsorção na zeólita HUSY somente do cátion metálico $\mathrm{Cd}^{2+}$, realizada em $\mathrm{pH} 7$ e em três temperaturas diferentes $25^{\circ} \mathrm{C}, 35^{\circ} \mathrm{C}$ e $45^{\circ} \mathrm{C}$. 

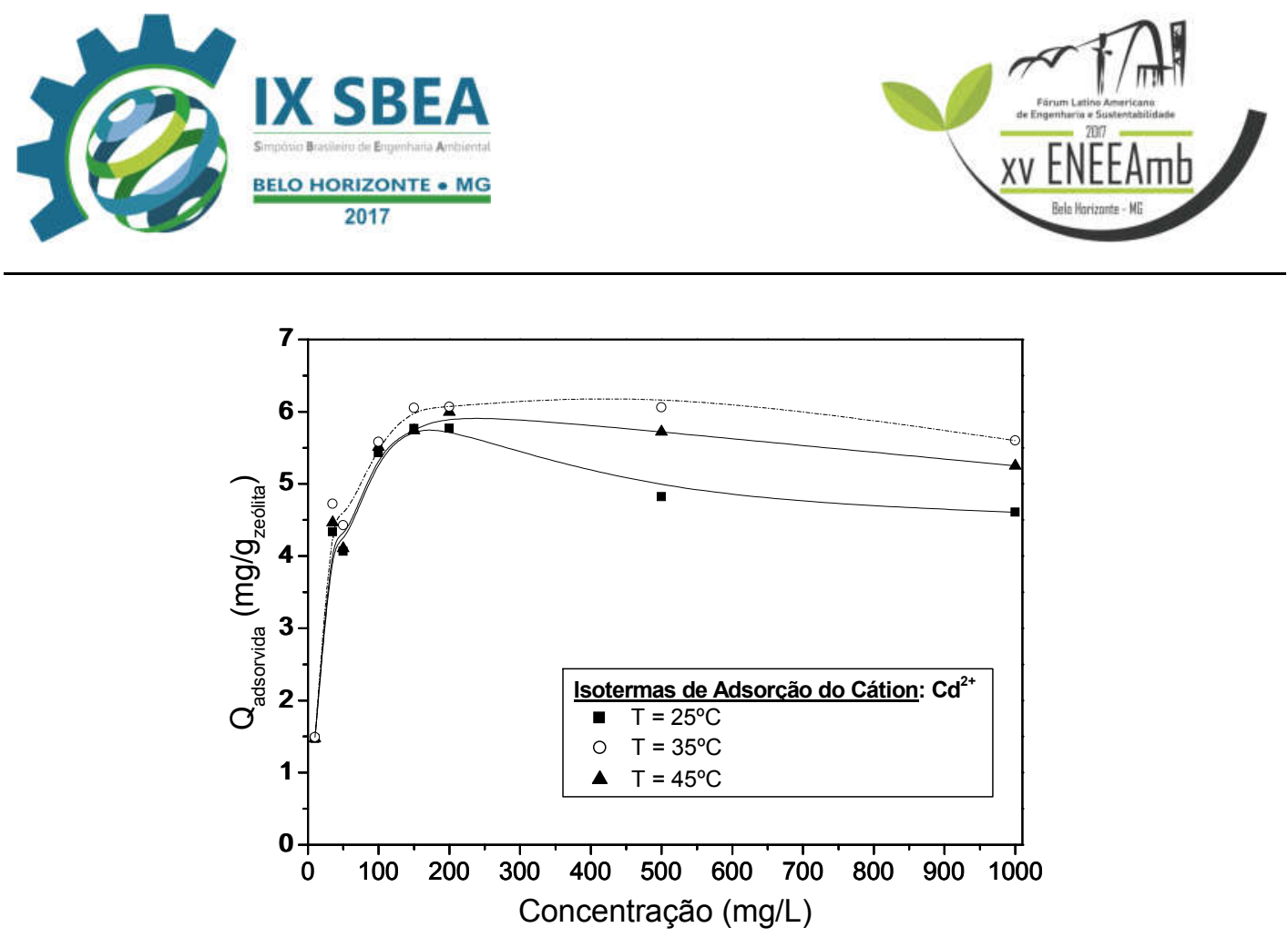

Figura 5 - Isotermas de adsorção do cátion $\mathrm{Cd}^{2+}$ sobre zeólita HUSY nas temperaturas de $25^{\circ} \mathrm{C}, 35^{\circ} \mathrm{C}$ e $45^{\circ} \mathrm{C} \mathrm{em} \mathrm{pH}=7$.

A partir da Figura 7 percebe-se que com o aumento da temperatura de $25^{\circ} \mathrm{C}$ para $35^{\circ} \mathrm{C}$ temos um aumento significativo na quantidade adsorvida do cátion $\mathrm{Cd}^{2+}$ na zeólita HUSY, aumentando posteriormente a temperatura para $45^{\circ} \mathrm{C}$, não se evidencia o aumento na adsorção, indicando possivelmente que a zeólita atingiu sua máxima capacidade de adsorção, ou seja, com o aumento da temperatura os cátions conseguem adsorver em sítios antes inatingíveis em temperaturas mais baixas, localizados nos microporos mais internos das zeólita. Esse mesmo comportamento foi verificado para os outros cátions metálicos estudados além do $\mathrm{Cd}^{2+}$ na zeólita HUSY.

\section{CONCLUSÕES/RECOMENDAÇÕES}

O estudo do processo de adsorção de cátions metálicos na zeólita HUSY consistiu na determinação do tempo de equilíbrio de adsorção de cada cátion metálico, no estudo do efeito do pH na adsorção e na criação de isotermas de adsorção à $25^{\circ} \mathrm{C}, 35^{\circ} \mathrm{C}$ e $45^{\circ} \mathrm{C}$. Através da determinação do equilíbrio de adsorção o tempo mínimo necessário para obtenção do equilíbrio de adsorção foi de 1 hora para o $\mathrm{Cu}^{2+}, \mathrm{Ni}^{2+}, \mathrm{Pb}^{2+}, \mathrm{Cr}^{3+}$ e o $\mathrm{Cd}^{2+} \mathrm{e}$ de 2 horas para o $\mathrm{Zn}^{2+}$ e $\mathrm{Co}^{2+}$. $\mathrm{O}$ estudo da influência do $\mathrm{pH}$ na adsorção não mostrou importância significativa nas zeólitas HUSY, sendo escolhido o $\mathrm{pH} 7$ para a continuidade do estudo. Com a variação da temperatura de adsorção infere-se que as zeólitas atingiram 

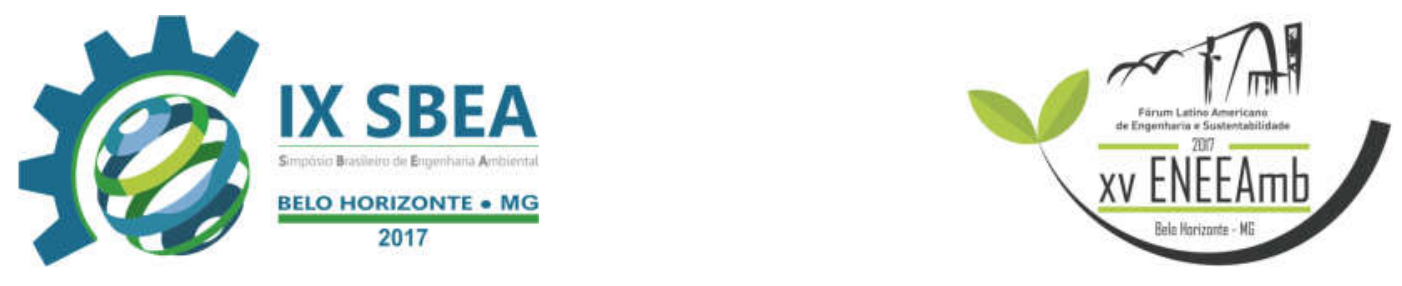

em $35^{\circ} \mathrm{C}$ sua máxima capacidade de adsorção, ou seja, com o aumento da temperatura os cátions conseguem adsorver em sítios antes inatingíveis em temperaturas mais baixas, localizados nos microporos mais internos das zeólita, até um certo limite de temperatura.

\section{REFERÊNCIAS BIBLIOGRÁFICAS}

AGUIAR, M.R.M.P.; NOVAES, A.C. Remoção de mateias pesados de efluentes industriais por aluminossilicatos. Química Nova. 2002, 25.

BRASIL. Conselho Nacional do Meio Ambiente. Resolução n 430, de 13 de Maio de 2011.

BRECK, D. Zeolite Molecular Sieves, Structure, Chemistry and Use, 1974, 552p.

FUNGARO, D. A.; SILVA, M. G. da; Quim. Nova 2002, 25, 1081.

JIMENEZ, R.S.; BOSCO, S.M.D.; CARVALHO, W.A. Remoção de metais pesados de efluentes aquosos pela zeólita natural escolecita - influência da temperatura e do $\mathrm{pH}$ na adsorção em sistemas monoelementares. Química Nova. 2004, 27.

JORDÃO, M. H. Catalisadores Bimetálicos e Bifuncionais para Isomerização do nHexano: Ni-Pt suportados na zeólita HY. São Carlos, UFSCar, 2001. 237 p.(Tese).

LUZ, A. B. Zeólitas: Propriedades e Usos Industriais. Rio de Janeiro: CETEM/CNPq (Série Tecnologia Mineral), 1995.

PERGHER, S.B.C; OLIVEIRA, A.C.L; SMANIOTTO, A; PETKOWICZ.I.D. Materiais Magnéticos Baseados em Diferentes Zeólitas para Remoção de Metais em Água. Química Nova, Vol 28, 2005.

PERGHER, S.B.C.; CAOVILLA, M.; DETONI, C.; MACHADO, N.R.C.F. Remoção de $\mathrm{Cu}+2$ de soluções aquosas em zeólita Nax. Efeito da granulometria. Química Nova. Vol 28, 2005.

SHINZATO, M.C. Remoção de metais pesados em solução por zeólitas naturais: revisão crítica. Revista do Instituto Geológico. 2007, 26-27.

SOBRINHO, E.V. Preparação e Caracterização da Zeólita Y com Alto Teor de Silício Obtida por Desaluminização em Série. 1993. 146 f. (Tese)

TAGLIAFERRO, G.V.; PEREIRA, P.H.F.; RODRIGUES, L.A.; da SILVA, M.L.C.P. Adsorção de Chumbo, Cádmio e Prata em Óxido de Nióbio (V) Hidratado Preparado pelo Método da Precipitação em Solução Homogênea. Química Nova. Vol. 34, 2011. 